\title{
ESBOZO DE UNA ANTROPOLOGÍA APOCALÍPTICA
}

\author{
Luis Fernando CARDONA SUÁREZ \\ Facultad de Filosofia \\ Pontificia Universidad Javeriana
}

«Aprended ahora un secreto a la vez inmenso y terrible. Corazón del hombre, tú eres la única salida por donde el río de la mentira y la muerte se introduce diariamente sobre la tierra. Tú eres el único paso por donde la serpiente emponzoñada levanta su ambiciosa cabeza, y por donde sus ojos gozan incluso de alguna luz elemental: porque su prisión está bien por debajo de la nuestra».

(Franz von Baader)

Schelling asume en 1809 la reflexión filosófica sobre la naturaleza del hombre a partir del desarrollo de su llamada metafísica del mal ${ }^{1}$. Sin lugar a dudas, esta novedosa metafísica, en la cual el ser esencial del hombre es conceptualizado desde la determinación real, y no meramente formal, de la libertad, se presenta como un intento original de fundamentación sistemática de la realidad

1 Este término fue utilizado por Martín Heidegger para caracterizar la investigación schellingiana de 1809 sobre la esencia de la libertad humana. A partir del estudio de Heidegger de 1936 la investigación especializada sobre Schelling ha asumido este término para designar el proyecto metafísico de Schelling en su Freiheitsphilosophie, diferenciándolo de los intentos idealistas de hacer de la filosofia trascendental kantiana una verdadera metafisica. "Una metafísica del mal es la fundamentación de la pregunta por el Ser como fundamento del sistema, el cual ha de ser erigido como sistema de la libertad. Según esto se busca una metafísica como fundamentación de la metafísica - una marcha circular - ciertamente. Ya Kant antes había hablado de la metafísica de la metafísica. Esta es para él la Crítica de la razón pura, para Schelling, la metafísica del mal." M. HEIDEGGER. Schellings Abhandlung über das Wesen der menschlichen Freiheit (1809). TÜBIngen 1971, 125. Cf. Chr. Schulte. Radikal Böse. Die Karriere des Bösen von Kant bis Nietzsche. München 1988, 208. 
del mundo (Weltansicht $)^{2}$ y como un esfuerzo especulativo de realizar una crítica a las pretensiones modernas de fundamentar el saber y el obrar en la experiencia aislada de una subjetividad omnipotente, que desde su mero ser racional se ha venido convirtiendo en el centro absoluto de toda determinación de lo existente. Es por ello que en el proyecto filosófico schellingiano de la Freiheitsschrift ${ }^{3}$ la metafísica del mal se convierte en una crítica radical al fundamento mismo de la modernidad, pues, para Schelling, ia idea moderna del sujeto como un punto arquimédico, desde el cual se pretende construir sólidamente el edificio entero del pensar, el obrar y el vivir, ha conducido inevitablemente al despliegue de un sistema filosófico y social de desolación y barbarie ${ }^{4}$.

Como se puede ver Schelling se ubica aquí en la tradición de la crítica a la racionalidad moderna, que marca de un modo decisivo el rumbo de la filosofía europea a lo largo del siglo XIX, y que incluso continúa viva aun en nuestro siglo. Esta crítica ha demostrado, de múltiples formas, cómo el primado metodológico y conceptual de la idea moderna de la búsqueda de la autoafirmación humana genera un reino pleno de la arbitrariedad, al pretender desplegar de una manera sistemática una voluntad universal de dominio sobre todo lo real. Es, precisamente, en esta voluntad subjetiva y aislada, que se asume en la acción particular del hombre como una voluntad universal legitimada moral y metafísicamente de una manera abstracta, donde Schelling cree encontrar el fundamento ontológico de todo comportamiento egoísta del hombre. La crítica al egoísmo de la acción humana, así se base ésta en una supuesta dignidad de la intencionalidad moral de la razón práctica o en un refinado cálculo instrumental de medios a fines en cada acción particular del hombre, es una constante en pensadores tan disímiles como, por ejemplo, Thomasius, Schelling, Schopenhauer, Nietzsche, Freud y Bloch 5 . En esta breve conferencia abordaremos la metafísica schellingiana del mal como el esbozo de una antropología apocalíptica, que en cuanto tal permite desarrollar

2 Cf. M. Heidegger. Schellings Abhandlung, 19.

3 Con la expresión Freiheitsschrift se cita corrientemente el famoso trabajo de Schelling de 1809 Philosophische Untersuchungen über das Wesen der menschlichen Freiheit und die damit zusammenhänganden Gegenstände. Este texto aparece reeditado en: F.W.J. SCHELLING. Sämmtliche Werke (S.W). Hrsg. M. SCHRÖTER. München 1958, Bd VII, 333-416.

i CF. P.L. OsterReich. Fundamentalrhetorik. Untersuchung zu Person und Rede in der Öffentlichkeit. Hamburg 1990, 124.

5 Cf. T. Kовusch. Die Entdeckung der Person. Metaphysik der Freibeit und modernes Menschenbild. Darmstadt 1997, 176. 
una crítica a los fundamentos ontológicos de la modernidad y a la idea secular de la autoafirmación humana.

En su escrito de 1809, titulado Philosophische Untersuchungen über das Wesen der menschlichen Freiheit und die damit zusammenhängenden Gegenstände, Schelling construye el marco onto-cosmológico desde el cual es posible desarrollar el esbozo de esta antropología: el fundamento creador, esto es, la natura naturans como condición de la natura naturata, se sumerge en el mundo para desde allí poder regresar de nuevo a su propio seno. En este movimiento de acción-reacción el fundamento creador se convierte en una especie de abismo ontológico (ontologischer Abgrund) ${ }^{6}$. Siguiendo la teosofía de Böhme, se puede representar este movimiento contradictorio del modo siguiente: al comienzo de la cosmogénesis hay una creación inconsciente de la materia, se trata de un estallido originario, la primerísima explosión creadora que brota de las entrañas mismas del fundamento de todo lo real, es decir, el universo que se expande en la materia y en el tiempo; después acontece el repliegue del fundamento sobre sí mismo, esto es, el retorno del fundamento a su propio centro. El ritmo fundamental que caracteriza esta cosmogénesis es la explosión-implosión o exhalación-inhalación ${ }^{7}$. Este ritmo es la característica esencial de todo ser vivo y, por lo tanto, del universo entero.

Gracias a este ritmo fundamental se da en todo lo que es vivo una interna y permanente contradicción entre caos y orden. Hay un orden en la naturaleza, y por ello es que nosotros podemos conocer sus diferentes fenómenos como acontecimientos ordenados de acuerdo con una ley inherente a ellos. Según los presupuestos del idealismo trascendental, esta ley tiene una relación estructural con el ordenamiento de nuestro entendimiento. En la naturaleza todo es orden, regla y tiene una forma. Pero hay también, al mismo tiempo, el presentimiento de una radical carencia de orden en el fundamento de las cosas. Se trata de una especie de caos creador, del cual todo proviene de una manera inexplicable, y ante el cual el más fino razonamiento metafísico manifiesta su impotencia radical, cuando quiere comprender lo que aquí sucede. Esto caótico es lo que en la tradición mística ha sido denominado como la base incomprensible de la realidad. En la Naturphilosophie schellingiana se produce una

6 Cf. M. HeIdegGer. Schellings Abhandlung, 163.

7 Cf. R. OHASHI. "Der Ungrund und das System (403-416)", en: O HÖFFE/ A PIEPER (Hrsg). F.W.J. Schelling. Über das Wesen der menschlichen Freiheit. Berlin 1995, 250. 
curiosa fusión entre filosofía trascendental y la mística cosmogónica de origen romántico, que permite aproximarse al fundamento enigmático y contradictorio de la realidad ${ }^{8}$.

Esta base, que no puede ser comprendida por el entendimiento, es precisamente el fundamento de la existencia. Aquí Schelling descubre, de una manera realmente magistral, el límite de la razón humana en su pretensión de explorar el origen y el fundamento último de lo real. Esto que escapa al entendimiento es, en cuanto tal, el principio mismo de la vida, que se despliega en cada momento tanto en el universo entero como en cada uno de los seres vivos. Este principio permanece oscuro, pues es algo anterior al entendimiento mismo y no puede ser captado en su origen tal como es, ya que nuestro entendimiento solamente puede captar aquello que es susceptible de ser reducido a un porqué, y esto originario adolece de todo porqué. Siguiendo, una vez más al místico Jakob Böhme, Schelling identifica esto originario con el fundamento oscuro de Dios, es decir, con lo infundado (Ungrud) ${ }^{9}$.

En esta ontocosmología Schelling ya no pregunta, como lo hacia antes en su idealismo trascendental, por el fundamento de la posibilidad de nuestro conocimiento de Dios, sino por el fundamento en Dios. Si Dios es el absoluto, no puede tener su fundamento en otra cosa distinta de él mismo; pero su fundamento, por su propia naturaleza, tiene que ser algo distinto de Dios mismo.

Esta situación paradójica es la que lleva a Schelling a sostener su revolucionaria tesis de la diferencia ontológica ${ }^{10}$. De acuerdo con su inicial Naturphilosophie, Schelling sostiene ahora que en todo aquello que decimos que es algo vivo, se puede establecer la distinción entre "el ser, en cuanto existe, y el ser en cuanto mero fundamento de la existencia" ". Siguiendo esta teoría de la diferencia ontológica, Schelling sostiene que en Dios, dado que no es un mero concepto abstracto o una simple substancia, tal como antes le había

8 Cf. J. Jantzen. "Die Philosophie der Natur", en: H.J. SandKüler (Hrsg). FW.J Schelling. Weimer 1998, 84 .

9 Cf. F.W.J. Schelling. Sämmtliche Werke, Bd VII, 406 (Freiheitsschrift).

10 Cf. M. HeIDEgGer. Die Metaphysik des deutschen Idealismus. Zur erneuten Auslegun von Schelling: Philosophischen Untersuchungen über das Wesen der menschlichen Freiheit und die damit zusammenhängenden Gegenstände (1809). Frankfurt am Main, 91.

11 F.W.J. SCHELLING. Sämmtliche Werke, Bd VII, 357 (Freibeitsschrift). 
pensado la metafísica occidental, debe haber algo distinto de él mismo que, sin embargo, es el fundamento de su existir. Cabe aquí recordar que, aunque el fundamento y la existencia son ontológicamente distintos, no por ello son separables en Dios, como sí sucede en todos los seres creados y, particularmente, en el hombre ${ }^{12}$.

Esta teoría de la diferencia ontológica le permite a Schelling comprender el proceso de la naturaleza como un proceso de evolución de la conciencia en la naturaleza. La conciencia es en cada momento ser consciente. En el hombre el ser ha alcanzado la dimensión de la autocomprensión. Pero este proceso, en el cual el ser ha llegado a ser lo que es a partir de su proceso de clarificación de su fundamento oscuro, es un proceso altamente contradictorio, pues la luz jamás puede penetrar e iluminar plenamente la oscuridad más profunda, en la cual la vida fluye en su fondo primigenio sin una determinación previa. El fondo de todo lo real, en cuanto fondo sombrío, es realmente una potencia contradictoria o indiferencia absoluta ${ }^{13}$, pues es lo que hace posible que algo sea y fluya, y, al mismo tiempo, es lo que pone en peligro todo lo existente, pues, en el centro de su oscuridad, lo que ha devenido fuera de sí es reintegrado en la nulidad de su concentración con aquello de lo cual se separo, en el proceso de su generación al inicio del tiempo. Es en este sentido que se puede decir que el proceso de la naturaleza es un proceso dramático y apocalíptico.

En el hombre este drama adquiere su máxima determinación, pues en él el aspecto negativo de la potencia, esto es, lo carente de regla, lo caótico, llega a ser plenamente consciente como acto libre. Es por ello que, solamente, en la libertad humana se da la opción de la nada, la negación de lo existente, el establecimiento del caos como efecto del obrar. Ciertamente, el hombre está empotrado en el ser, pero puede sentir el deseo de separarse de él, de destruirlo. En esto consiste, precisamente, el mal. Por el poder de su libertad el hombre puede llegar a convertirse en el cómplice del Dios invertido ${ }^{14}$. En la libertad humana el abismo en Dios y el abismo del mal están estructuralmente relacionados. El hombre, efectivamente, se relaciona con Dios, pero esto pertenece a su condición de criatura; también tiene una relación con el principio oscuro del Dios

12 Cf. F.W.J. Schelling. Sämmtliche Werke, Bd VII, 361-362 (Freiheitsschrift).

13 Cf. W. BEIERWALTES. "Absolute Identität. Neuplatonische Implikationen in Schellings Brunom, en: Identität und Differenz. Frankfurt am Main 1980, 236.

14 Cf. F.W.J. SchEll.ING. Sämtliche Werke, Bd VII, 390 (Freiheitsschrift). 
creador, con su incompletud caótica. El hombre, en cuanto ser escindido que mendiga su existencia desde la plena excentricidad, ${ }^{15}$ en su búsqueda de convertirse en Prometeo establece la ley de Dionisio sobre lo existente, desgarrando no solamente todo lo que lo rodea, sino estableciendo también la desolación en el centro de su corazón ${ }^{16}$.

Las especulaciones metafísicas schellingianas son narraciones, que a partir de los conceptos propios de la tradición mística alemana, asumidos filosóficamente, quieren acercarse al devenir caótico de la realidad humana y del enigma de la libertad. Aquello que no puede ser tematizado por el entendimiento, solamente puede ser captado de un modo narrativo. De un modo particular, la historia narra cómo la naturaleza en el hombre actúa con los ojos abiertos, afirmando de un modo consciente los secretos que ella guarda en su seno; la historia narra, también, cómo Dios en el despliegue temporal de sus potencias se busca a sí mismo. Es por ello que, para Schelling, la historia no es otra cosa que el proceso temporal de la autorrevelación interna de Dios. En este proceso se afirma a un Dios vivo, que en su autodevenir es, al mismo tiempo, el devenir verdadero de la naturaleza, esto es, un despliegue de la naturaleza hacia su forma plena, así como una semilla despliega toda su potencia creadora al convertirse en la planta que encierra en su interior.

Este despliegue convierte a Dios, y a su creación, en una unidad viviente que afirma en cada momento los dolores del devenir, la facticidad del tiempo, la fragilidad de la existencia, pues el Dios schellingiano no es una mera categoría abstracta o una simple entidad moral ${ }^{17}$, tal como antes le había pensado el idealismo alemán, sino un Dios que, como ocurre en la tradición gnóstica clásica, sufre humanamente y se somete a las inclemencias del devenir y del tiempo ${ }^{18}$. En este sentido, no se puede identificar a la creación por sí misma, y de un modo inmediato, como algo originariamente

15 Cf. H. Plessner. Mit anderen Augen. Aspekte einer philosophischen Anthropologie. Stuttgart 1982, 24.

16 Cf. H.U. Von Balthasar. Prometheus. Studien zur Geschichte des deutschen Idealismus. Heidelberg 1947, 204.

17 Cf. F.W.J. Schelling. Sämmtliche Weke, Bd VII, 411 (Freiheitsschrift).

I8 Cf. F. VON BAADER. "Vorlesungen über spekulative Dogmatik», en: Sämmtliche Werke. Hrsg. von F. HoffMAnN. Leipzig 1987, Bd 8, 170. P. KosLowSKI. "Die Lehre vom freiwillig leidenden Gott als christliche Theodizee", en: Gnosis und Theodizee. Eine Studie über den leidenden Gott des Gnostizismus. Wien 1989, 107. 
bueno, pues desde un comienzo, en su fundamento oscuro, contiene el principio propio del mal; sin embargo, ello no quiere decir que Dios mismo sea la fuente y la causa de la existencia del mal en el mundo. Esto sucede así, porque el autodevenir de Dios y de la naturaleza es un proceso libre, que contiene en su interior la posibilidad del mal y que en el despliegue histórico de su facticidad, al final del tiempo, debe alcanzar la plena superación del mal. Schelling aquí se distancia notablemente de la concepción idealista de la libertad como mera autonomía y autoafirmación moral del hombre, pues, para el Schelling de la Freiheitsschrift, el concepto real, y no meramente formal, de la libertad es aquel que encierra en su interior también la opción del mal. Así, la libertad se convierte aquí en "una capacidad para el bien y para el mal»" ${ }^{19}$.

Después de haber expuesto el contexto ontocosmológico desde el cual es posible el esbozo de su antropología apocalíptica, Schelling se concentra en desarrollar la narración que pone en evidencia el despliegue propio de la libertad humana. Tal como las ha caracterizado Rüdiger Safranski, las investigaciones schellingianas sobre la esencia de la libertad humana son, realmente, la narración del drama interno de la realización de la libertad del hombre, que pone en evidencia el exceso estructural de la libertad ${ }^{20}$. Schelling caracteriza el drama de la libertad a partir del escenario de la voluntad, pues es aquí donde se establece el conflicto estructural entre la voluntad propia (Eigenwille) y la voluntad universal (Universalwille). Este conflicto interno de la voluntad, que se concentra en el corazón mismo del hombre, es el escenario de la polaridad del proceso completo del mundo en el despliegue de su potencialidad interna ${ }^{21}$. Como ya se anotó anteriormente, la narración del drama de la libertad humana no es simplemente un ejercicio especulativo estéril del filósofo, pues, desde la descripción de la estructura ontológica que fundamenta el drama de la voluntad, Schelling ofrece aquí los elementos conceptuales para desarrollar su crítica a la concepción moderna del hombre como un ser autofundamentado y autoconsistente.

En su Freiheitsschrift de 1809, Schelling modifica notablemente las consideraciones metafísicas tradicionales sobre la naturaleza última de lo real, al

19 F.W.J. SCHELling. Sämmtliche Werke, Bd VII, 352 (Freiheitsschrift).

20 Cf. R. SAFRANSKI. "Das Böse oder das Drama der Freiheit", en: K.P. LIESSMANN (Hrsg). Faszination des Bösen. Über die Abgründe des Menschlichen. Wien 1997, 32.

21 Cf. R. Safranski. Das Böse oder das Drama der Freiheit. München 1997, 66. 
afirmar que el "querer es el ser originario (Wollen ist Ursein)» ${ }^{22}$. Como lo anota Heidegger, esta formulación permite caracterizar las investigaciones metafísicas schellingianas como el desarrollo de una metafísica de la voluntad ${ }^{23}$, que yendo más allá de la mera determinación formal de la acción moral del hombre y de su principio supremo, según el idealismo moral de corte kantiano, el imperativo categórico, ofrece una perspectiva crítica radical sobre el comportamiento egoísta del hombre y sobre las condiciones reales que lo hacen posible como un comportamiento socialmente aceptado.

Para Schelling, todo ser vivo se mueve necesariamente en una polaridad interna; esta polaridad es la que constituye la tensión estructural que caracteriza a todo querer, pues todo ser vivo está determinado en su obrar por dos principios fundamentales que se contraponen de un modo permanente. El primer principio es la mismidad. Cada ser individual tiene su centro de gravedad en su propio egoísmo. Una parte de la fuerza de la vida está unida a este principio y es utilizada para la afirmación de la existencia y para la autoconservación de la vida propia del individuo en cada una de sus acciones. Lo viviente tiene la aspiración de permanecer en sí y para sí. Según este primer principio, la vida es un movimiento de contracción. Schelling considera que el concepto de Dios es el concepto de la metafísica tradicional que más capta la naturaleza de este movimiento; pero si solamente se diera en Dios este aspecto, no se habría dado creación alguna. Cada ser individual obedece a una tendencia interna para conservar su forma $y$, con ello, sus limitaciones originarias. Gracias a este principio se da en cada individuo su específico encerramiento originario, las tinieblas que lo retienen en el fundamento oscuro de su existencia. Este principio se manifiesta de una manera especial en el desarrollo de la materia, pues toda la materia inanimada está dominada en su fundamento por la gravedad ${ }^{24}$.

El segundo principio es la fuerza expansiva. Todo ser vivo tiende a salir fuera de sí, a exceder sus propios límites; este salir es, precisamente, el primer paso hacia la autotrascendencia. Aquí el individuo busca una relación con el

22 F.W.J. SCHELLING. Sämmtliche Weke, Bd VII, 350 (Freiheitsschrift).

23 Cf. M. HeIDEgGer. Die Metaphysik des deutschen Idealismus, 84.

24 Cf. H. Krings. "Genesis und Materie - Zur Bedeutung der Timaeus- Handschrift für Schellings Naturphilophie", en: F.W.J. Schelling. Timaeus (1794). Schellingiana, Bd. 4. Hrsg. W.E. EHRHARDT: Stuttgart- Bad Cannstatt 1994, 150. 
mundo, que le permita afirmar su existencia de un modo autoconsciente. Cuando este principio de expansión alcanza su máxima determinación espiritual, se convierte en el amor (Liebe) que inunda a todo lo creado. ${ }^{25}$ Se trata aquí de una fuerza centrífuga que busca su afirmación, alejándose de su centro originario de gravedad. Este es el principio que constituye a la conciencia en su despliegue histórico; por este motivo es la conciencia, en tanto en cuanto forma primordial de la trascendencia, la que domina la historia como manifestación abierta del despliegue de la vida. La conciencia abre la duración del mundo.

La relación de estos dos principios es la que determina, en la Naturphilosophie schelllingiana, la comprensión dialéctica del mundo ${ }^{26}$. El mundo no es otra cosa que la relación dialéctica entre lo carente de consciencia y lo consciente, lo real y lo ideal, la materia y el espíritu, la mismidad y el amor ${ }^{27}$. Esta dialéctica expresa el misterio fundamental del querer; y por ello es que Schelling considera que la vida está atravesada permanentemente por la tensión originaria entre la voluntad propia y la voluntad universal. El principio de acción que proviene del fundamento oscuro es la voluntad propia de la criatura, es decir, la voluntad que quiere permanecer concentrada en su propio centro. En su esfuerzo de autoconcentración, esta voluntad impide el despliegue pleno del amor y, por lo tanto, de la posibilidad de expansión de su centro hacia la voluntad universal.

El concepto de la voluntad universal no designa aquí simplemente la voluntad divina, de la cual todo lo real proviene y por medio de la cual todo permanece cohesionado, sino que nombra el devenir a la claridad de la voluntad, pues gracias a esta voluntad universal el ser vivo recibe aquella luz, de la que carece su fundamento de existencia. También este concepto señala el tránsito de la voluntad ciega a la voluntad determinada ya no por su egoísmo natural, sino

25 Por esta razón es que Guido Vergauwen ha caracterizado el proyecto metafísico schellingiano como el desarrollo especulativo de una metafísica del amor. Cf. G. VERGAUWEN. Absolute und endliche Freiheit. Schellings Lehre von Schöpfung und Fall. Freiburg 1975, 60.

26 Cf. W. HaRTKOPF. Studien zur Entwicklung der moderne Dialectik. Die Dialectik in Schellings Ansätzen zu einer Naturphilosophie. Meisenheim am Glan 1972, 245.

27 La relación entre la mismidad y el amor ya había sido antes enunciada por Hölderlin como el centro problemático de una genuina comprensión filosófica de la esencia del mundo. Schelling asume ahora esta idea para darle un carácter sistemático a su reflexión metafísica sobre la esencia de la libertad humana. Cf. D. HENRICH. "Eine philosophische Konzeption entsteht. Hölderlins Denken in Jena», en: Hölderlin-Jahrbuch, 28 (1992-1993), 1-28. 
por el principio supremo de la concentración en la vida universal. La voluntad universal es, realmente, una transformación esencial del querer, esto es, su propia autotrascendencia. Siguiendo el método de la analogía antropomórfica de Eschenmayer ${ }^{28}$, Schelling identifica ahora la voluntad universal con el entendimiento (Verstand), ya que el entendimiento es propiamente una capacidad espiritual, orientada hacia la autotrascendencia no sólo del individuo, sino también de la especie entera ${ }^{29}$.

Para poder explicar la manera cómo estos dos principios se manifiestan en cada uno de los seres vivos, Schelling se vale una vez más de su teoría de la diferencia ontológica. La mayoría de los seres naturales permanecen encerrados en el fundamento oscuro de su existencia, sin poder alcanzar la luz del entendimiento. Pero es en el hombre donde, por primera vez, se desarrolla de una manera descomunal la voluntad propia, provocando así un conflicto estructural entre ambas voluntades. En el hombre se da, al mismo tiempo y con la misma fuerza, el poder de las tinieblas y la fuerza entera de la luz; en él hay el abismo más profundo y el cielo más alto, es decir, ambos centros ${ }^{30}$.

Siguiendo la antropología mística de Franz von Baader, Schelling considera que el hombre es un ser intermedio: un ser intermedio entre Dios y la naturaleza ${ }^{31}$. Dado que Dios solamente puede revelarse en el ser libre que actúa a partir de sí mismo, la palabra divina sólo es pronunciada en el hombre, y sólo en él se abre Dios como espíritu, pues el hombre es el único ser creado independiente de la naturaleza. Pero el hombre es también, al mismo tiempo, independiente de Dios, en la medida en que él, como espíritu finito creado, a partir del no-existente relativo tiene una raíz independiente de Dios en la naturaleza, y con ello está colocado en un punto de indiferencia absoluta ${ }^{32}$.

Schelling piensa aquí esta indiferencia no de un modo negativo, como la asume la metafísica clásica de corte neoplatónico, sino como un poder positivo y vivo para el bien y para el mal, pues en el fundamento oscuro de la naturaleza

28 Cf. F.W.J. SCHELling. Sämmtliche Werke, Bd VIII, 207 (Briefwechsel mit Eschenmayer). J. Habermas. Das Absalute und die Geschichte. Von der Zwiespältigkeit in Schellings Denken. BONn 1954, 227. M. Frank. Unendliche Annäherung. Die Anfäge der philosophischen Frühromantik. Frankfurt am Main 1997, 428.

29 Cf. F.W.J. Schelling. Sämmtliche Werke, Bd VII, 359 (Freiheitsschrift).

30 Cf. F.W.J. Schelling. Sämmtliche Werke, Bd VII, 363 (Freiheitsschrift).

31 Cf. F.W.J. Schelling. Sämmtliche Werke, Bd VII, 433 (Stuttgarter Privatvorlesungen).

32 Cf. F.W.J. Schelling. Sämmtliche Werke, Bd VII, 460 (Stuttgarter Privatvorlesungen). 
de Dios radica la condición trascendental de la posibilidad de la libertad humana. Por esta posición intermedia, el hombre se encuentra en todo momento en una situación precaria ${ }^{33}$.

El conflicto de la voluntad en el hombre consiste en que la voluntad particular quiere devorar a la voluntad universal, y el egoísmo aspira aniquilar la expresión del amor. La superación del egoísmo significa, entonces, el restablecimiento del amor como principio originario de la acción. La posibilidad de esta superación convierte al hombre en el verdadero redentor (Erlöser) de la naturaleza, pues solamente en él se puede producir el restablecimiento de la unidad originaria y armónica de los principios ${ }^{34}$. Pero para que esta unidad sea de nuevo establecida, es necesario que el hombre asuma, con toda radicalidad, en el centro de su corazón, la voluntad de amor como principio auténtico de acción en cada una de sus actos particulares. De este modo Schelling reformula con su lenguaje romántico la doctrina moral kantiana del imperativo categóri$\mathrm{co}^{35}$. Cuando el egoísmo comanda a la razón, la capacidad humana de la autotrascendencia se reduce a la mera autoafirmación instrumental de la existencia. La historia humana ofrece innumerables ejemplos del significado de este proceso. El desarrollo desmedido de la racionalidad científica y técnica puede ser explicado ahora a partir de este proceso de sumisión de la voluntad del amor al egoísmo indiscriminado de la existencia humana ${ }^{36}$.

Una de las tareas de la libertad es, para Schelling, la conservación del ordenamiento de la posición de los principios. Según esta antropología apocalíptica, el hombre es realmente un traidor (Verräter) de sus principios supremos de vida ${ }^{37}$. Pero esta condición de ser traidor no proviene de su ser natural, sino de la libertad misma. "El animal nunca puede salir de la unidad, mientras que el hombre puede desatar cuando quiere el eterno vínculo de fuerzas» ${ }^{38}$. Schelling reformula aquí de un modo metafísico la sentencia del místico Franz von Baader, cuando afirma que el hombre debe aprehender un secreto

33 Cf. R Safranski. Das Böse, 69.

34 Cf. F.W.J. Schelling. Sämmtliche Werke, Bd VII, 411 (Freiheitsschrift).

35 Cf. H. Von ZeltNer. Schelling. Stuttgart 1954, 261.

36 Cf. N: Bolz. "Das Böse. Jenseits von Gut und Böse", en: Philosophie nach ihrem Ende. München 1992, 11-28.

37 Cf. H. Von ZeltNer. "Der Mensch in der Philosophie Schellings", en: Studia Philosophica, 14 (1954), 211-224.

38 F.W.J. SCHELling. Sämmtliche Werke, Bd VII, 373 (Freiheitsschrift). 
a la vez inmenso y terrible. "Corazón del hombre, tú eres la única salida por donde el río de la mentira y la muerte se introduce diariamente sobre la tierra. Tú eres el único paso por donde la serpiente emponzoñada levanta su ambiciosa cabeza, y por donde sus ojos gozan incluso de alguna luz elemental: porque su prisión está bien por debajo de la nuestra» ${ }^{39}$. Según esta antropología mística, el hombre es un colaborador del mal, pero no un absoluto agente único de éste.

En la medida en que el hombre se halla situado en una cima en la que tiene dentro de sí la fuente interna de su automovimiento hacia el bien y, al mismo tiempo, hacia el mal, el vínculo de los principios en él no es necesario, sino libre ${ }^{40}$. Por esta situación el hombre siempre se encuentra ante una encrucijada. En su acción particular el hombre deviene el traidor de la voluntad universal, porque en sus acciones determinadas la angustia de la vida lo lleva a conservar siempre su propio centro. Pero el centro de todo lo existente es el espíritu del amor, aquel fuego devorador (verzehrendes Feuer), en el cual toda particularidad muere; por ello, para conservar su propia mismidad, el hombre busca incansablemente salir del verdadero centro a la periferia, buscando allí reposo. De este modo el hombre que busca su consuelo en la periferia se convierte en un ser excéntrico. El apartarse del verdadero centro es la traición del espíritu, el establecimiento de la hybris como principio de acción ${ }^{41}$.

Este mecanismo de la traición es el dispositivo ontológico del mal que se desata en todos los comportamientos que consideramos como moralmente malos o injustos. Este dispositivo es el escándalo, que en la tradición cristiana era asumido antes como el pecado permanentemente renovado contra el Espíritu Santo, esto es, el empecinado desconocimiento de la fuerza vinculante del espíritu del amor ${ }^{42}$. El hombre solamente es pecador ante el espíritu del amor, que es propiamente el centro de todo ser viviente. El hombre es un animal metafísico, y cuando pierde el impulso originario de buscar su autotrascendencia en el amor, traiciona así su propio principio de vida.

39 F. VON BAADER. "Vorlesungen über spekulative Dogmatik», en: Sämmtliche Werke, Bd II, 344-345.

40 Cf. F.W.J. SCHELling. Sämmtliche Werke, Bd VII, 374 (Freiheitsschrift).

41 Cf. M. MAENGEL. «Die unreine Quelle. Zu einer Ontologie der Hybris», en: A. SCHuLler/ W. vON RAHDEN (Hrsg). Die andere Kraft. Zur Renaissance des Bösen. Berlin 1993, 324.

42 Cf. E.DrewERMANN. Strukturen des Bösen. Die jahwistische Urgeschichte in philosophischer Sicht. München 1995, Bd III, 504. 
A mediados del siglo XIX, el mismo Schelling experimentó esta traición del espíritu en manos de la ciencia moderna, que tendía cada vez más hacia una positivización de todo saber. En el desarrollo del naturalismo científico y del materialismo ve Schelling los signos inequívocos de una historia de perversión del saber y de traición del principio supremo de todo conocimiento: el vínculo originario con el amor, que solamente se puede alcanzar a partir de la renuncia de todo aquello que se quiere mantener como algo aislado, esto es, separado de un principio supremo de vida realmente vinculante ${ }^{43}$.

Schelling ve en el desarrollo de la ciencia moderna el despliegue de una actitud desoladora frente a la existencia, y particularmente frente a la vida y al destino final del hombre, pues la racionalidad que la fundamenta se ha venido separando, cada vez más, del principio mimético que antes había inspirado el nacimiento de la filosofía y la religión en la cultura griega. De este modo, la narración de la estructura ontológica del drama propio de la libertad humana permite elaborar una crítica al fundamento de despliegue de la ciencia y de su racionalidad claramente positiva.

En su teoría de la traición del espíritu, Schelling también bosqueja una crítica política a la estructuración de las sociedades modernas. El término que permite desplegar esta crítica no es otro que el de la inversión de los principios (Verkehrung der Prinzipien), que es precisamente la formulación schellingiana del dispositivo originario del mal que opera en la acción humana egoísta ${ }^{44}$. La inversión de los principios, esto es, el dominio del egoísmo sobre la voluntad del amor impide que el conjunto de los hombres, separados unos de otros, pueda encontrar una unidad que cohesione la pluralidad intraducible de los individuos. Esta dispersión hostil en la multiplicidad del egoísmo origina la necesidad de una búsqueda de una unidad secundaria, que haga posible un entendimiento recíproco y vivo ${ }^{45}$.

43 Cf. W. SCHMIED-KOWARZIK. "Die existentiell-praktische Einheit von Mensch und Natur. Zur Bedeutsamkeit der Naturphilosophie Schellings für die Ökologiedebatte", en: R. HECKMANN/ H. KRINGS/ R.W. MEYER (Hrsg). Natur und Subjektivität. Zur Auseinandersetzung mit der Naturphilosophie des jungen Schelling. Referate, Voten und Protokolle der II. Internationallen Schelling-Tagung, Zürich 1983. Stuttgart 1985, 387.

44 Un análisis detenido del significado de este término en la filosofía schellingiana se encuentra en mi disertación. C. L.F. CARDONA. Inversión de los principios. La teoria schellingiana de la positivitad del mal. Santafé de Bogotá 1998.

45 Cf. J. AlBERG. Die verlorene Einheit. Die Suche nach einer philosophische Alternative zu der Erbsündenlebre von Rousseau bis Schelling. Frankfurt am Main 1996, 224. 
Esta unidad secundaria es la organización del estado más allá de la unidad con la naturaleza perdida y con aquella unidad aún no alcanzada en Dios ${ }^{46}$. El estado es así una consecuencia de la pérdida del hombre de su dignidad divina. Sin la unidad de la naturaleza y sin la unidad con Dios, queda tan sólo la posibilidad de una unidad del estado, alcanzada artificialmente por medio de la violencia física o de la seducción de la argumentación racional. Esta unidad precaria, en cuanto es temporal, ansia los motivos espirituales de la verdadera unidad eterna; y por ello el espíritu deviene en ella ideología, al pretender el estado cohesionar a los hombres con sus egoísmos constitutivos en una unidad legal de coerción y dominio.

Por el carácter precario de tal unidad alcanzada en el estado, la unidad de la comunidad se desintegra de nuevo, desplegándose una vez más en la turba carente de un auténtico principio unificador. Para Schelling, la unidad conseguida por el estado es siempre una unidad incompleta y finita, que no logra hacerle frente a la anarquía promovida por el principio egoísta de la acción en cada hombre. Solamente la unidad alcanzada en el principio supremo de la moralidad, esto es, la religiosidad como conciencia escrupulosa (Gewissenhaftigkeit), ${ }^{47}$ puede realmente promover la neutralización del egoísmo como principio particular de acción $^{48}$.

El destino histórico del estado oscila entre el polo de la anarquía de la turba gentium y el del terror del orden de la más férrea legalidad moral y jurídica. Los intentos de armonizar las diferencias de los individuos en una comunidad de legalidad temporal se ven afectados por la precariedad de los vínculos de la comunidad humana. Para Schelling, el estado es simplemente una organización que tiene como interés no la protección de la verdadera vida, sino la propiedad y la supervivencia del individuo; y por ello no puede frenar la traición del espíritu, que significa socialmente la destrucción de la dignidad humana ${ }^{49}$.

46 Cf. FJ. WeTz. Friedrich W.J. Schelling. Zur Einführung. Berlin 1996, 79-95.

47 Cf. F.W.J. Schelling. Sämmtliche Werke, Bd VII, 392 (Freiheitsschrift).

48 Cf. W.E. EHRHARDT. «Freiheit ist unser und der Gottheit Höchstes. -Ein Rückweg zur Freiheitsschrift?" en: H.M BAUMGARTNER/ W.G. JACOBS (Hrsg). Schellings Weg zur Freiheitsschrift. Legende und Wirklichkeit. Akten der Fachtagung der internationalen Schelling-Gesellschaft 1992. Schellingiana, Bd 5. Stuttgart-Bad Cannstatt 1996, 240-251.

49 Cf. A. HOLLERBACH. "Schellings Rechts-und Staatsbegriff in den Jahren 1796-1800", en: M. FranK/ G. Kurz (Hrsg). Materialien zu Schellings philosophischen Anfangen. Frankfurt am Main 1975, 307-325. 
Dado que el dispositivo ontológico del mal radica en la inversión de los principios, su superación debe consistir en una revolución antropológica del corazón. Schelling identifica esta revolución con el retorno de la dignidad moral del hombre y con el fortalecimiento de la belleza heroica del individuo, esto es, con el establecimiento de la conciencia escrupulosa como único criterio verdadero de la acción moral ${ }^{50}$. Esta conversión antropológica es la que permite recuperar el equilibrio entre el fundamento oscuro y la luz de la existencia, entre la voluntad propia y la voluntad del amor, pues así como la enfermedad es la metáfora del mal, el equilibrio es la expresión de la verdadera vida ${ }^{51}$. La verdadera vida es el retorno de la mismidad a la luz, el entusiasmo por el bien o elevación extraordinaria por encima de sí mismo, heroísmo en la lucha contra el mal, fe en el sentido de una confianza suprema en la fuerza vinculante de la divinidad ${ }^{52}$.

Si el signo característico del espíritu maligno es la destrucción, pues es un ejercito sublevado de las concupiscencias, que instaura la discordia sobre todo lo existente ${ }^{53}$, lo distintivo ahora de esta conversión antropológica es la ternura o espíritu del amor, pues solamente el gesto tierno puede contrarrestar el espíritu de la traición, que se ha venido desplegando en occidente bajo la figura de la subjetividad moderna. Este espíritu de la discordia es la característica más esencial de la bestia rubia que, de acuerdo con Nietzsche, ha esparcido sobre toda la naturaleza su voluntad de dominio, afirmando su supremacía sobre todo lo existente ${ }^{54}$.

En su crítica a la racionalidad moderna Martín Heidegger asume la intención crítica de esta antropología apocalíptica schellingiana, cuando en su estudio sobre la obra poética de Georg Trakl sostiene que el hombre habitante del país de la tarde (Abendland) ${ }^{55}$ se ha convertido en algo extraño sobre la tierra.

50 Cf. S. PEETz. Die Freiheit im Wissen. Eine Untersuchung zu Schellings Konzept der Rationalität. Frankfurt am Main 1995, 77.

51 Cf. P.L. Oesterreich. Das gelehrte Absolute. Metaphysik und Rhetorik bei Kant, Fichte und Schelling. Darmstadt 1997, 163.

52 Cf. F.W.J. SCHelling. Sämmtliche Werke, Bd VII, 392 (Freiheitsschrift); Bd VII, 429430 (Stuttgarter Privatvorlesungen); Bd VI, 556-558 (Würzburger Vorlesungen).

53 Cf. F.W.J. Schelling. Sämmtliche Werke, Bd VII, 365 (Freiheitsschrift).

54 Cf. F. NieTZSCHE. "Zur Genealogie der Moral», en: Sämmtliche Werke. K. Schlechta (Hrsg). Darmstadt 1958, Bd II, 786.

55 Para HeidegGer, el término alemán Abendland designa a occidente, así como la expresión Morgenland significa el país de la mañana, esto es, oriente. 
Este extrañamiento radica en el hecho de que su existencia se ha perdido en la duplicidad de su estirpe, no pudiendo reconocer la dignidad de lo auténticamente espiritual ${ }^{56}$. Para Heidegger, al igual que para Schelling, solamente la mirada tierna de aquel que en un giro cambia su mirar, para captar el declinar de la tarde y poder así levantar su alma hacia la contemplación de la primavera azul, puede restablecer la unidad originaria de la vida, pues, como sucede en el Apocalipsis de San Juan, la verdadera fuerza unificante de la vida y del amor es el alfa y omega de todo lo existente, lo primero y lo último, el principio y el fin ${ }^{57}$.

56 Cf. M. Heidegger. Unterwegs zur Sprache. Pfullingen 1959, 59-60.

57 Cf. Apocalipsis de San Juan, XXII-13, en: Sagrada Biblia. Tr. P. Petisco S.J. Barcelona $1989,1471$. 